\title{
THE INFLUENCE OF EXERCISE METHOD AND REACTIONS TIME TO SKILLS SPRINT 100 METERS
}

\author{
Raffly Henjilito $^{1}$, Moch. Asmawi ${ }^{2}$, James Tangkudung ${ }^{3}$ \\ State University of Jakarta \\ raffly henjilito@yahoo.co.id ${ }^{1}$ \\ asmawi.moch@yahoo.co.id ${ }^{2}$ \\ jamestangkudung@unj.ac.id ${ }^{3}$
}

\begin{abstract}
The purpose of this research was determine the effect of free variables that the method of exercise and the moderator variable reaction time of the dependent variable of 100 meters. The research was done by using experimental method. Target population (research population) are male student of physical education, health and recreation islamic university of riau 2016/2017 123 people. Sampling was done by purposive sampling technique. The hypothesis is 1) difference between group of interval training method (A1) with group of continuous training method (A2) equal to 0,0245 < 0,05, mean $h_{0}$ rejected. 2) The difference between group of interval training method (A1) and group of mixed exercise method (A3), value $=0,0015<0,05$, means $h_{0}$ rejected. 3) The difference between the continuous training method group (A2) and the mixed exercise method group (A3), worth $=0.1345>0.05$, means $h_{0}$ received. 4) The interaction effect of fo $(A B)$ worth $=0,000<0.05$ means $h_{0}$ is rejected. 5) Differences in 100 meters of skill results between interval training methods with high reaction time and continuous training method with high reaction time $(A 1 B 1-A 2 B 1)$ valued at $0.000<0.05$ means $h_{0}$ is rejected. 6) Differences in 100 meters of skill result between interval training method with high reaction time and mixed reaction method with high reaction time $(A 1 B 1-A 3 B 1)$. Value $=0,000<$ 0,05 means $h_{0}$ is rejected. 7) Differences in 100 meter running skills results between continuous training method with high reaction time and high mixed reaction method (A2B1-A3B1) method = $0,000<0,05$ means $h_{0}$ is rejected. 8) Differences in the results of 100 meter running skills between interval training methods with low reaction time and continuous training method with low reaction time $(A 1 B 2-A 2 B 2)$ valued $=0.413>0.05$ means $h_{0}$ received. 9) Differences in the results of 100 meter running skills between interval training methods with low reaction time and mixed reaction method with low reaction time $(A 1 B 2-A 3 B 2)$ worth $=0.0155<0.05$ means $h_{0}$ is rejected. 10) The difference of 100 meter running skill result between continuous training method with low reaction time and mixed reaction method with low reaction time $(A 2 B 2-A 3 B 2)$ worth $=0,026<0,05$ means $h_{0}$ is rejected.
\end{abstract}

\section{Keywords: Skills Sprint 100 Meters, Exercise Method And Reaction Time}

Exercise has an important meaning in the effort to improve the quality of human resources. Sport can not be separated from human life, because human life consists of two aspects, namely the physical aspects and spiritual aspects that can not be separated. If these two aspects grow and grow in harmony there will be a harmonious life in its growth. The harmony of physical and spiritual life in man can be achieved by doing sport.

Thus the sport has a goal to maintain and improve fitness and can instill moral values and noble character, sportsmanship, and so forth. Many things to do in order to have a healthy body and fit, namely through sports activities such as athletics.

Athletics is one of the oldest sports, which has been done by humans since ancient times until today. It can even be said since the existence of human on this earth athletics already exists, because the movements contained in athletic sports, such as walking, running, jumping, and throwing is a movement performed by humans in everyday life. Basically almost all sports games are athletic 
elements such as running, resisting, jumping and so on. Therefore, it is not excessive to say that athletics is the mother of all sports.

The athletic sports branch consists of several numbers namely road, jump and throw. Running consists of running short distance, medium range running, long distance running and marathon. Running short distance has running numbers such as running 50 meters, 100 meters run, 200 meters run and run 400 meters.

Running 100 meter sprint is a capability that marked the process of moving the body position from one place to another quickly. Thus, to produce a fast run, the things to note are: the body posture leaning forward, footsteps should be longer, the hand swing should be in accordance with the movement of the foot and arm movement where the fingers clenched or opened tightly and relaxed . This is intended for maximum speed can be reached up to the finish line.

Some absolute factors determine whether the sprint sprinter is bad there are three things: start, sprint movement (when running), and finish. The basic technique is fundamental that must be mastered by all students in order to run quickly based on the ability of multilateral motion. The exercise that needs to be developed on the runners is the ability of the right basic technique with good basic physical skills. Therefore, each lecturer is required to understand the training stages from the aspect of the exercise so as to know when and how much the training portion. Runners who have the ability to run a good technique run will be able to use it in various situations, thus providing ease in applying tactics, then able to create maximum results to achieve victory.

Regular and programmed exercises done from an early age will make basic techniques run better. Exercise is certainly not only running techniques but also other techniques, as well as exercise tactics and flisik exercises. Varied exercises will create an atmosphere that is not boring exercise that raises an interest to diligently practice running motion. This exercise program is one form of exercise that contains the exercises, techniques, techniques and skills performed sequentially starting from the practice of running with interval training, running techniques with continuous training and running techniques with Mix exercises at each training session.

Interval training is an exercise system that alternates between performing hard (interval work) with periods of activity with low intensity (interrupted period) in a training phase.

Interval training is an exercise performed between heavy and light exercise in turn. Therefore in this method requires careful supervision of the duration of practice and rest periods. The rest time is arranged in such a way that no total recovery occurs.

Interval training is an exercise or training system interspersed with intervals in the form of periods of istrahat. So in practice is rest-exercise-rest-exercise-rest, and so on. Interval training is a training system interspersed by intervals (breaks), so Interval training is an exercise interspersed with a break between each rehearsal. Interval training is a form of exercise in the form of a series of exercises that are crossed by a period of time to perform other activities that are lighter.

It can be concluded that the interval method is an exercise method performed in the interval between exercise and rest. Based on this method the form of rest has significance, which is based on active rest and passive rest. This rest period is very useful for the body to restore the physical condition to its original state. This means that when doing the next activity the body is in optimal condition.

As Istvan Balyi et al says about the duration of the exercise it is recommended to be between 5 and 20 seconds, and full recovery must occur between sets.

In the interval training for repetition the exercises are performed at a greater intensity than Vo2max, with the working interval usually lasting between 30 and 90 seconds. Due to the high dependence on anaerobic metabolism, it takes a long recovery time between the same sessions. The recovery period is about four to six times during the working interval, resulting in a job: the rest ratio is about $1: 5$. 
In continuous english dictionary means continuous menerus, whereas continuously is with no ceasing, with ceaselessly, continuously canal. According to bruce continuous can be proved that continuous exercise is done without rest. Meanwhile, according to continuous exercise kalyani is a continuous exercise involving longer exercise duration at lower intensity.

In general, the activity of the continuous training method of the burden is long. Short length of loading time depends on the reality (reality) of the duration of sports activities performed. The longer the time it takes for the sport, the longer it takes for the burden or exercise, and vice versa.

Characteristics of continual method is in executing the exercise done with intensity and constant, and in the implementation of relatively long when compared with other methods. Continuous methods are recommended for training requirements for overall endurance improvement and improvement in resistance to fatigue.

Continuous training can be further defined by intensity exercise. Lower sustained exercise intensity is typically in the range of $70 \%$ to $80 \% \mathrm{VO} 2$ max for athletes, and $50 \%$ to $60 \% \mathrm{VO} 2$ max for those seeking fitness related to health. Lower intensity of continuous exercise can be used in a variety of situations, including developing health-related fitness for the average adult or during the early season of aerobic exercise in many sports.

Continuous exercise is not necessary at a constant speed but may vary within the given training session. short bursts of high intensity due to the exercise of both anaerobic and aerobic glycolytic energy systems, longer periods of slower exercise induce adaptation especially in aerobic systems, increasing the removal of lactic acid produced during high-intensity exercise.

Mixed training method is a strageri applied in the exercise to focus more on the target we want so that it can produce as much as possible. In the 100 meter run the combined method used is the continiuous training method with the inerval method.

Exercise with continiuous methods with low intensity use a lot of fat as a source of energy. Therefore, the exercise with the model stores muscle glycogen. Continiuous exercise lasts for a long time and will produce aerobic adaptation well. Continiuous exercises (eg, running continuously without rest) usually last for long periods, continuous runs that are more than 30 minutes under tempo below the anaerobic excitatory threshold will produce aerobic adaptation well.

Exercise with interval method is closely related to recovery because the two terms have the same meaning, namely the provision of rest time given during inter sets or between reps (repetition). Interval training is an exercise method interspersed by break intervals. Interval training for speed is usually high intensity $80-90 \%$ of the maximum ability, otherwise interval training for endurance is usually the intensity of the low to medium running intensity of about $50 \%-70 \%$ of the maximum ability.

Mixed training method is a combination method of continiuous method and interval method. The combination method is a gradual exercise method of exercising the continiuous method to the interval method back again to a technique that is a complete movement technique.

Continiuous-interval-continiuous training model is also called combination or continiuous method and interval method. In continiuous-interval-continiuous models, subjects are trained with skills continiuous and combined into intervals and trained using segmentation, simplification, or practical methods. so that when the results of the exercise will be better if students train a continiuous movement first to give a general idea of the skills, and then break the skills into intervals.

It can be synthesized from the above opinion that the mix training method is a combination of interval and continiuous methods trained in students with continiuous skills after which it is broken down into intervals and rehearsed repeatedly in each sed and repetitions

Physical component factors that are needed in the sport is one of speed. Speed in many sports requires a component of speed and is a very essential physical component. At the athletic sports speed is also very important to achieve a high performance improvement that is with the speed of reaction to 
achieve the best time results in a race. In the various branches of sports speed is a component of essential physical condition. as in athletic sports especially running 100 meters, the reaction speed is very important role, especially at the start or leave the start.

Reaction time is defined as the elapsed time between receiving the stimulus and the immediate and unexpected reaction given to it; however, the reaction time changes based on factors such as age, sex, condition, fatigue, high altitude, alcohol, nicotine and the use of physcotroptic substances.

In the reaction speed is the initial capacity of body movement to receive stimuli suddenly or quickly. The speed of the reaction is the ability to answer stimulus or stimulus acoustically, and tactile quickly. While Sukadiyanto said the speed of reaction is the ability of a person in answering a stimulus in the shortest time possible.

Reaction speed is a quality that allows starting a kinetic response as quickly as possible after receiving a stimulus. So the speed of the reaction can also be interpreted as a tool organism's ability to answer a stimulus as quickly as possible in achieving the best results.

The speed of the reaction is the time between the arrival of the stimulus with the initial movement. For example, the reaction time of a person sprinted at the start of the beam is since the pistol goes off (with the signal !!) with the sprinter out of the start block until the sprinter targets the first leg to the track.

The rate of reaction is the shortest time required to give a kinetic answer after receiving a stimulus. This relates to reflex time, movement time, and response time. The time of motion differs from the reaction time in the thinking process. In the reflex impulse is transmitted from the sensory nerve center of the reflex and subsequently to the efferent nerve, then to the effector.

At the time of reaction there is the process of thinking, because the stimuli that come brought to the central nervous system by the nerves efferent and delivered by the nerve afferent to the effector. The movement time is the time taken from the moment the motion until the creaking ends. Response time is the amount of reflex time and time of motion.

Thus it can be deduced that the rate of reaction is the speed of answering a stimulus quickly and can be a vision, sound through hearing. In other words the ability of a muscle or a group of muscles to react as quickly as possible after getting a stimulus.

The speed of the reaction is the time difference between physical action and stimulation sent by the nervous system from the muscles. The shorter the time it reaches means the higher the level of reaction. On the grounds that an athlete must be able to give a decision of immediate action possible over the occasion that occurred at the same time. The speed of a foot reaction does not mean simply moving the legs quickly, but it can also be limited to moving the legs in the shortest or shortest time.

This study aims to determine the effect of free variables that is the method of exercise and the moderator variable reaction speed of the dependent variable that is 100 meters running skills. By the operational objectives of this study are to derive empirical facts about:

1. Differences results of 100 meter running skills using interval method with continuous method on Student Health education and recreation Faculty of Vocational Science of Islamic University of Riau?

2. Differences in the results of 100 meter running skill using interval method with mix method on Student Health education and recreation Faculty of Vocational Science of Islamic University of Riau? Islamic University of Riau?

3. Differences result of 100 meter running skill using continuous method with mix method on Student Health education and recreation Faculty of Vocational Science of Islamic University of Riau? Riau Islamic University? 
4. Interaction between exercise method and reaction speed to 100 meter running skill on student Health education and recreation Faculty of Vocational Science of Islamic University of Riau? Islamic University of Riau.

5. Differences of 100 meters running skill result between interval training method with high reaction speed with continuous training method with high reaction speed in students Health education and recreation Faculty of Vocational Science of Islamic University of Riau? Islamic University of Riau.

6. Differences of 100 meter skill result between interval training method with high reaction speed with mixed exercise method with high reaction speed in students Health education and recreation Faculty of Vocational Science of Islamic University of Riau? Riau Islamic University.

7. Differences of 100 meters running skill results between continuous training method with high reaction speed with mixed exercise method with high reaction speed in the students Physical education health and recreation Faculty of Vocational Science Islamic University of Riau? Riau Islamic University.

8. Differences of 100 meter running skill result between interval training method with low reaction speed with continuous training method with low reaction speed on student Health and recreation physical education Faculty of Vocational Science Islamic University of Riau.

9. Differences of 100 meter running skill result between interval training method with low reaction speed with continuous training method with low reaction speed in student Health and recreation physical education Faculty of Vocational Science Islamic University of Riau.

10. Differences of 100 meters running skill results between continuous training methods with low reaction speeds with mixed exercise methods with low reaction speed in students Physical education health and recreation Faculty of Vocational Science Islamic University of Riau.

\section{METHOD}

The research was done by using experimental method. This research consist of dependent variable that is 100 meter running skill and free variable of treatment is exercise method and moderator variable that is reaction speed. This research will be at Sports Venue Athletics Islamic University of Riau Road Kharudin Nasution Marpoyan. While the implementation time is done with the frequency 3 times a week ie Monday, Wednesday and Saturday. The research design used is the factorial treatment plan $2 \times 3$, where the independent variables are classified into 3 (three). The treatment-free variables were classified in three forms of exercise method (A) with interval training method (A1), continuous training method (A2) and mixed exercise method (A3). While the independent variables are classified into two levels of reaction velocity (B) ie high reaction speed (B1) and low reaction rate (B2). The design of factorial treatment $2 \times 3$ can be explained as the following table:

Table 1. Treatment design factorial $2 \times 3$

\begin{tabular}{|l|l|l|l|}
\hline \multicolumn{1}{|c|}{$\begin{array}{l}\text { Exercise Method (A) } \\
\text { Reaction speed }(\mathrm{B})\end{array}$} & $\begin{array}{l}\text { Interval } \\
\left(\mathbf{A}_{\mathbf{1}}\right)\end{array}$ & $\begin{array}{l}\text { Continuous } \\
\left(\mathbf{A}_{2}\right)\end{array}$ & $\begin{array}{l}\text { Mix } \\
\left(\mathbf{A}_{3}\right)\end{array}$ \\
\hline Height (B1) & $\mathrm{A}_{1} \mathrm{~B}_{1}$ & $\mathrm{~A}_{2} \mathrm{~B}_{1}$ & $\mathrm{~A}_{3} \mathrm{~B}_{1}$ \\
\hline Low (B2) & $\mathrm{A}_{1} \mathrm{~B}_{2}$ & $\mathrm{~A}_{2} \mathrm{~B}_{2}$ & $\mathrm{~A}_{3} \mathrm{~B}_{2}$ \\
\hline Total & & & \\
\hline
\end{tabular}

Source: James Tangkudung, Kinds of Research Methodology. (Jakarta: Lens Media Media Indonesia, 2016) p. 154 
Information:

A1B1 = Group interval method given to participants having high reaction rate.

$\mathrm{A} 2 \mathrm{~B} 1=$ Group of continuous methods given to participants having high reaction speed.

$\mathrm{A} 3 \mathrm{~B} 1=$ Group of mix methods given to participants who have high reaction speed .

A1B2 $=$ Group of interval methods given to participants having low reaction rates.

$\mathrm{A} 2 \mathrm{~B} 2=$ Group of continuous methods given to participants having low reaction rates.

$\mathrm{A} 3 \mathrm{~B} 2=$ Group of mix methods given to participants having low reaction rates.

Population used as target population (research population) is student of Penjaskesrek Universitas Islam Riau Force 2016/2017 counted 123 people. Sampling is done by purposive sampling technique. In accordance with the research design, there are two kinds of data that must be collected: (1) data about 100 meter running skill, and (2) data about reaction speed. To obtain data about the speed of running 100 meters and the data rate of reaction then performed tests and measurements. To measure 100 meters running skills by running as fast as possible with a distance of 100 meters and reaction speed measured with Whole Body Reaction. In accordance with the research design experiments treatment factorial $2 \times 3$ then hypothesis testing is done by using the analysis of variance (ANAVA) two lanes. However, before the analysis is done then first will be done some testing. Furthermore the frequency distribution is visualized through tables and histograms. Furthermore, the test requirements analysis is tested normality and homogeneity test. the group's 100 meter run was taught with interval training methods higher than in the mixed-mixed group.

\section{RESULTS}

The summary of 100 meters of skill difference between students taught by interval training method (A1), continuous training method (A2) and mixed exercise method (A3) in accordance with the hypothesis proposed by the researcher. The summary hypothesis will be explained in the following interpretation:

First Hypothesis: Differences Between Group Interval Exercise Methods (A1) With Groups of Continuous Exercise Methods (A2). In contrast the above table can be analyzed the price t0 (A1 X $\mathrm{A} 2)=-2.011, \mathrm{p}$-value $=0.049 / 2=0.0245<0.05$, means $\mathrm{H} 0$ rejected. Thus, the group's 100 meter sprint skill taught with interval training methods is higher than in the group given continuous training methods.

Second Hypothesis: Differences Between Groups of Interval Exercise Methods (A1) With Group Mix Exercise Method (A3). In contrast (A1 X A3) can be analyzed the price of t0 (A1 X A3) = -3.126 , p-value $=0.003 / 2=0.0015<0.05, \mathrm{H} 0$ is rejected. Thus, the group's 100 meter running skills taught by interval training methods were higher than those in the mixed exercise method.

The third hypothesis: Differences Between Groups of Continuous Exercise Methods (A2) With the Mix Method Training Group (A3).

Further on the third hypothesis, the contrast table (A2 X A3) can be analyzed ie the price of t0 $(\mathrm{A} 2 \mathrm{X} \mathrm{A} 3)=-1,116, \mathrm{p}$-value $=0.269 / 2=0.1345>0.05, \mathrm{H} 0$ is accepted. Thus, the group's 100 meter running skill taught by continuous training methods is similar to that of the mixed-practice group.

Fourth Hypothesis: Interaction Effect Fo $(\mathrm{AB})=27.147$ with p-value $=0,000<0.05$ or $\mathrm{H} 0$ is rejected. This means there is a very significant interaction effect between factor A (exercise method) and factor B (reaction speed) on the 100 meter running skill of the student. It can be seen from the analysis that the influence of variable of exercise method and reaction speed on 100 meter running skill is RSquared $=0,547 \times 100=54,70 \%$.

Fifth Hypothesis: Differences in 100 meters of skill results between interval training methods with high reaction speed and continuous training method with high reaction speed (A1B1 - A2B1). 
Difference between group t0 $(\mathrm{A} 1 \mathrm{~B} 1-\mathrm{A} 2 \mathrm{~B} 1)=4.052$, $\mathrm{p}$-value $=0,000 / 2=0,000<0,05$ or $\mathrm{H} 0$ is rejected. Thus, the average group of students taught by interval training methods is higher than in the group of students taught by continuous training methods for high-speed reaction students.

Sixth Hypothesis: Differences in 100 meters of skill results between interval training methods with high reaction speed and mixed reaction method with high reaction rate (A1B1 - A3B1).

The difference between the groups t0 $(\mathrm{A} 1 \mathrm{~B} 1-\mathrm{A} 3 \mathrm{~B} 1)=8.162$, $\mathrm{p}$-value $=0,000 / 2=0,000$ $<0.05$ or $\mathrm{H} 0$ is rejected. Thus, the average group of students taught by interval training methods is higher than in the group of students who were taught by the mix exercise method for high-speed student reaction groups.

The Seventh Hypothesis: Differences in 100 meters of skill results between continuous training methods with high reaction speed and mixed reaction method with high reaction speed (A2B1 - A3B1).

The difference between the groups t0 $(\mathrm{A} 2 \mathrm{~B} 1-\mathrm{A} 3 \mathrm{~B} 1)=4.110, \mathrm{p}$-value $=0,000 / 2=0,000$ $<0.05$ or $\mathrm{H} 0$ is rejected. Thus, the average group of students taught by continuous training methods is higher than in the group of students who were taught by mixed exercise methods for high-speed student reaction groups.

Eighth Hypothesis: Differences in 100 meters of skill results between interval training methods with low reaction rates and continuous training methods with low reaction rates (A1B2 A2B2).

The difference between the groups t0 $(\mathrm{A} 1 \mathrm{~B} 2-\mathrm{A} 2 \mathrm{~B} 2)=-0.222$, $\mathrm{p}$-value $=0.826 / 2=0.413 \mathrm{P}$ 0.05 or $\mathrm{H} 0$ is accepted. Thus, there is no difference in the average 100-meter running skill between groups of students taught by interval training methods with groups of students taught by continuous training methods for low-speed student groups.

Ninth Hypothesis: Differences in 100 meters of skill results between interval training methods with low reaction rates and mixed reaction method with low reaction speed (A1B2 - A3B2).

Difference between group t0 $(\mathrm{A} 1 \mathrm{~B} 2-\mathrm{A} 3 \mathrm{~B} 2)=-2.206$, $\mathrm{p}$-value $=0,031 / 2=0,0155<0,05$ or $\mathrm{H} 0$ is rejected. Thus, the average group of students taught by the interval training method is lower than the group of students who were taught by the mix exercise method for low-speed student group reactions.

Tenth Hypothesis: Differences in 100 meters running skill results between continuous training methods with low reaction speed and mixed reaction method with low reaction speed (A2B2 - A3B2).

The difference between the groups t0 $(\mathrm{A} 2 \mathrm{~B} 2-\mathrm{A} 3 \mathrm{~B} 2)=-1.985$, p-value $=0.052 / 2=0.026$ $<0.05$ or $\mathrm{H} 0$ is rejected. Thus, the average group of students taught with continuous training methods is lower than in the group of students who were taught by the mixed practice method for low-speed reaction students.

Looking at the model and regression function above can be concluded that the influence of exercise method and reaction speed to 100 meter running skill at student of Penjaskesrek Islamic University of Riau. It can also be seen and summarized by researchers in summary of the decomposition of all hypothesis test results of differences between groups of methods exercise (A) and the result of hypothesis testing of group differences of exercise method with reaction rate (AB). This summary can be seen in the following table:

Table 2. Summary of Decomposition of All Hypothesis Test Results

\begin{tabular}{|l|l|l|l|l|l|l|}
\hline No & Hypothesis & $\mathbf{t}_{\mathbf{0}}$ & Fo & p-value & \multicolumn{2}{|l|}{ Information } \\
\hline 1 & $\mathrm{~A} 1-\mathrm{A} 2$ & $-2,011$ & & $0,0245<0,05$ & $\mathrm{H}_{0}$ is rejected & $\mathrm{A} 1>\mathrm{A} 2$ \\
\hline 2 & $\mathrm{~A} 1-\mathrm{A} 3$ & $-3,126$ & - & $0,0015<0,05$ & $\mathrm{H}_{0}$ is rejected & $\mathrm{A} 1>\mathrm{A} 3$ \\
\hline 3 & $\mathrm{~A} 2-\mathrm{A} 3$ & $-1,116$ & - & $0,1345<0,05$ & $\mathrm{H}_{0}$ be accepted & $\mathrm{A} 2<\mathrm{A} 3$ \\
\hline
\end{tabular}




\begin{tabular}{|l|l|l|l|l|l|l|}
\hline 4 & $\begin{array}{l}\text { Interaction } \\
\mathrm{AXB}\end{array}$ & - & 27,147 & $0,000<0,05$ & $\mathrm{H}_{0}$ is rejected & Significant \\
\hline 5 & $\mathrm{~A}_{1} \mathrm{~B}_{1}-\mathrm{A}_{2} \mathrm{~B}_{1}$ & 4,052 & - & $0,000<0,05$ & $\mathrm{H}_{0}$ is rejected & $\mathrm{A}_{1} \mathrm{~B}_{1}>\mathrm{A}_{2} \mathrm{~B}_{1}$ \\
\hline 6 & $\mathrm{~A}_{1} \mathrm{~B}_{1}-\mathrm{A}_{3} \mathrm{~B}_{1}$ & 8,162 & - & $0,000<0,05$ & $\mathrm{H}_{0}$ is rejected & $\mathrm{A}_{1} \mathrm{~B}_{1}>\mathrm{A}_{3} \mathrm{~B}_{1}$ \\
\hline 7 & $\mathrm{~A}_{2} \mathrm{~B}_{1}-\mathrm{A}_{3} \mathrm{~B}_{1}$ & 4,110 & - & $0,000<0,05$ & $\mathrm{H}_{0}$ is rejected & $\mathrm{A}_{2} \mathrm{~B}_{1}>\mathrm{A}_{3} \mathrm{~B}_{1}$ \\
\hline 8 & $\mathrm{~A}_{1} \mathrm{~B}_{2}-\mathrm{A}_{2} \mathrm{~B}_{2}$ & $-0,221$ & - & $0,413>0,05$ & $\mathrm{H}_{0}$ be accepted & $\mathrm{A}_{1} \mathrm{~B}_{2}<\mathrm{A}_{2} \mathrm{~B}_{2}$ \\
\hline 9 & $\mathrm{~A}_{1} \mathrm{~B}_{2}-\mathrm{A}_{3} \mathrm{~B}_{2}$ & $-0,206$ & - & $0,0155<0,05$ & $\mathrm{H}_{0}$ is rejected & $\mathrm{A}_{1} \mathrm{~B}_{2}<\mathrm{A}_{3} \mathrm{~B}_{2}$ \\
\hline 10 & $\mathrm{~A}_{2} \mathrm{~B}_{2}-\mathrm{A}_{3} \mathrm{~B}_{2}$ & $-1,985$ & - & $0,026<0,05$ & $\mathrm{H}_{0}$ is rejected & $\mathrm{A}_{2} \mathrm{~B}_{2}<\mathrm{A}_{3} \mathrm{~B}_{2}$ \\
\hline
\end{tabular}

So 1). Group of interval training method (A1) with group of continuous training method (A2) worth $0,0245<0,05$, mean $\mathrm{h} 0$ is rejected. 2 ). The difference between group of interval training method (A1) and group of mixed exercise method (A3), value $=0,0015<0,05$, means h0 rejected. 3 ). The difference between the continuous training method group (A2) and the mixed practice method group (A3), worth $=0.1345>0.05$, means h0 is accepted. 4). The influence of interaction (interaction effect) fo $(\mathrm{AB})$ worth $=0,000<0.05$ means h0 is rejected. 5). Differences in 100 meters of skill results between interval training methods with high reaction speed and continuous training method with high reaction rate (A1B1 - A2B1) worth $0.000<0.05$ means $\mathrm{H} \neg \mathrm{O}$ is rejected. 6). Differences in 100 meter running skill results between interval training method with high reaction speed and mixed reaction method with high reaction rate (A1B1 - A3B1). Value $=0,000<0.05$ means h0 is rejected. 7). Differences in 100 meter running skill results between continuous training method with high reaction speed and mixed reaction method with high reaction speed $(\mathrm{A} 2 \mathrm{~B} 1-\mathrm{A} 3 \mathrm{~B} 1)=0,000<0,05$ means $\mathrm{h} 0$ is rejected. 8). Differences in the results of 100 meter running skills between interval training methods with low reaction speed and continuous training method with low reaction speed (A1B2 - A2B2) valued $=0.413>0.05$ means h0 received. 9). Differences in the results of 100 meter running skills between interval training methods with low reaction speed and mixed reaction method with low reaction speed (A1B2 - A3B2) worth $=0.0155<0.05$ means h0 is rejected. 10). The difference in skill results is 100 meters between continuous training method with low reaction speed and mixed reaction method with low reaction speed (A2B2 - A3B2) worth $=0,026<0,05$ means h0 is rejected.

\section{DISCUSION}

\section{Differences Between Exercise Interval Methods With Continuous Training Methods On 100} meter Running Skills In Student Physical Education Health and Recreation Faculty of Teacher Training And Education Islamic University of Riau. (A1 x A2)

Based on the results of the analysis of research data on the first hypothesis, it was stated that there is a difference in skill value of 100 meters run significantly between the group of interval training methods with the group of continuous training methods.

In contrast value of both treatment groups there is $\mathrm{p}$-value value that is 0,0245 . When compared to the 0.05 or $5 \%$ significance standard p-value $0.0245<0.05$ means $\mathrm{H} 0$ is rejected and $\mathrm{H} 1$ is accepted. So it can be concluded that there is a difference in literary skills value of 100 meters between groups of interval training method with continuous training method group and 100 meters student skill score trained with superior / higher interval training method than group value trained by method continuous training on student Physical Education Health and Recreation Faculty Of Teacher Training And Education Islamic University of Riau.

Based on the process of training method, interval training method is an exercise or training system interspersed with intervals of rest period. So in practice is rest-exercise-rest-exercise-rest, and so on. For example, the first meeting on the interval training material is running 30 meters $(5 x), 60$ meters $(4 x), 80$ meters $(3 x)$ and 100 meters $(2 x)$ with a break between repeat 8 seconds and rest between sets of 3 minutes. So when the student has done the first run 30 meters, the student rests 8 
seconds first, then can enter the next repository as much as $5 \mathrm{x}$. Then to move the set from 30 meters to 60 meters students are required to rest 3 minutes, just enter the set of 60 meters, and so on up to the set of 100 meters.

Thus, based on the results of the above research, the researchers recommend that the interval training method is higher than the effect of continuous training method in an effort to improve the 100 meter running skills.

\section{Differences Between Exercise Interval Methods With Mix Practice Method Of Skills Running 100 meters In Student Physical Education Health and Recreation Faculty Of Teacher Training And Education Islamic University of Riau. (A1 x A3)}

The exercise method used in this study is basically to improve the 100 meter running skill on short distance runs in athletic sports. From the results of the analysis of the above exercise methods when observed the implementation will result in 100 meters of running skills on students Physical Education Health and Recreation Faculty Of Teacher Training And Education Islamic University of Riau.

The results of interval training method analysis with mixed exercise method was seen based on the result of variance analysis that was to see the difference between the group trained by the interval training method with the group of students who were trained by mixed practice method and the result taken from both groups was 100 meter skill test. Furthermore, after seeing the difference between the group of interval training methods with mixed training methods then held further tests using t-dunnet test.

In contrast value of both treatment groups there is $\mathrm{p}$-value value is 0.0015 . When compared to the 0.05 or $5 \%$ significance standard then p-value $0.0015<0.05$ means $\mathrm{H} 0$ is rejected and $\mathrm{H} 1$ accepted. So it can be concluded that there is a difference of 100 meter skill score significantly between group of interval training method with group of mixed practice method and 100 meters student skill score which is trained by interval method is superior / higher than the group value trained by method mixed exercise at student Physical Education Health and Recreation Faculty Of Teacher Training And Education Islamic University of Riau.

Thus based on the results of research and the results of the above analysis, it turns out the value of student skills trained with interval training methods is superior to the mix practice method. therefore the researchers recommend that the interval training method is higher than the effect of the mix exercise method in an effort to improve the 100 meter running skills.

\section{Differences Between Continuous Training Methods With Mix Training Methods Of 100m Running Skills In Student Physical Education Health and Recreation Faculty Of Teacher Training And Education Islamic University of Riau. (A2 x A3)}

In the group of students who were trained with continuous training methods and mixed exercise methods did not have a significant difference. In contrast value of both treatment groups there are $\mathrm{p}$-value value that is 0,1345 . When compared to the 0.05 or $5 \%$ significance standard $\mathrm{p}$-value $0.1345>0.05$ means $\mathrm{H} 0$ is accepted and $\mathrm{H} 1$ is rejected. So it can be concluded that there is no difference in the value of literary 100 meter running skill between group of continuous training method with group of practice mix method and 100 meters student skill score which is trained by high / low continuous training method with group value trained by practice method mix on students Physical Education Health and Recreation Faculty of Teacher Training And Education Islamic University of Riau.

Thus based on the results of the research and the results of the above analysis, it turns out the value of student skills trained by the method of continuous training is superior to the method of mix practice. therefore the researchers recommend that the method of continuous exercise is higher than the effect of the mix exercise method in an effort to improve the 100 meter running skills. 


\section{Effect of Interaction Between Method Exercise and Speed of Reaction To Skill Run 100 meter at student Physical Education Health and Recreation Faculty of Teacher Training And Education Islamic University of Riau.}

From result of analysis and hypothesis testing between method of practice (A), hence subsequent researcher determine how big of interaction between method of exercise (A) with reaction speed (B) on 100 meter running skill student of Faculty Of Teacher Training And Education Islamic University of Riau.

Based on the results of analysis of research data, stated that there is interaction between training method (A) with student reaction speed (B). In the Interaction Test value of both groups $(\mathrm{AxB})$ there is a value $\mathrm{Fo}(\mathrm{AB})=27.147$ with $\mathrm{p}$-value $=0,000<0.05$ or $\mathrm{H} 0$ is rejected. This means there is a very significant interaction effect between factor A (exercise method) and factor B (reaction speed) on 100 meter running skill at student Physical Education Health and Recreation Faculty of Teacher Training And Education Islamic University of Riau.Furthermore, it can be seen from the result of analysis that the influence of variable of exercise method and reaction speed to 100 meter running skill is R-Squared $=0,547 \times 100=54,70 \%$.

Thus the hypothesis test result proved that there is interaction analysis between the training method such as interval training method, continuous training method and mixed exercise method (A) with reaction speed (B) to 100 meter running skill at student Physical Education Health and Recreation Faculty Of Teacher Training And Education Islamic University of Riau. So it can be concluded that the interaction between interval training methods, continuous training methods and mixed exercise methods.

From the above description, it can be interpreted that the high interaction between training methods trained with interval training methods, continuous training methods and mixed exercise methods in students with high-speed reaction as well as low-speed reaction students. Thus it can be concluded that the interaction between training methods and the speed of reaction to 100 meter running skills on students Physical Education Health and Recreation Faculty Of Teacher Training And Education Islamic University of Riau.

\section{Differences of $\mathbf{1 0 0}$ meters running skill result between interval training method with high reaction speed with high-speed continuous training method in student of Physical Education Health and Recreation Islamic University of Riau (A1B1xA2B1).}

Based on the results of the research data analysis on the fifth hypothesis, it is stated that there is a difference in 100 meter skill score significantly between the high-speed reaction interval group and the high-speed continuous training group.

From the results of the analysis of the above exercise methods when observed the implementation of both produce 100 meters of running skills on students Physical Education Health and Recreation Faculty of Teacher Training and Education Islamic University of Riau. The result of analysis of interval training method with continuous training method in high student category of reaction is seen based on the result of variance analysis that is to see the difference between two groups trained by interval training method with group of students trained by continuous technique method of high speed reaction student category. Furthermore, after observing the difference between the group of interval training method and the continuous training method, a further test using the tdunnet test is performed, the analysis test calculated how big the difference between 100 meter running skill value between the two groups of interval training method with group continuous practice group high on students Physical Education Health and Recreation Faculty of Teacher Training And Education Islamic University of Riau.

In contrast of value of both treatment groups there is p-value value is 0.000 . When compared to the 0.05 or $5 \%$ significance standard p-value $0,000<0.05$ means $\mathrm{H} 0$ is rejected and $\mathrm{H} 1$ is accepted. So it can be concluded that there is a difference in literary skills value of 100 meters between group of 
interval training method with continuous training method group and 100 meters student skill score trained with interval method is superior / higher than the group value trained by method continuous training on student Physical Education Health and Recreation Faculty of Teacher Training And Education Islamic University of Riau.

Thus, based on the results of the above research and analysis, the researchers recommend that the interval training method is higher than the effect of continuous training method in the category of students with high-speed reaction in improving the 100 meter running skills.

\section{Differences in the Outcome of $\mathbf{1 0 0}$ meters Running Skills Between High Speed Reaction} Group Interval Training Methods With High Speed Reaction Mix Group Practices In Student Physical Education Health and Recreation Islamic University of Riau(A1B1XA3B1).

The results of interval training method analysis with mixed exercise method was seen based on the result of variance analysis that was seen the difference between the group trained by interval training method and the group of students who were trained by the mixed exercise method in the highspeed reaction group of students. Furthermore, after seeing the difference between the group of interval training methods with the method of mixture of high reaction speed reaction group then held further test using t-dunnet test.

In contrast of value of both treatment groups there is $p$-value value is 0.000 . When compared to the 0.05 or $5 \%$ significance standard then p-value $0,0000<0.05$ means $\mathrm{H} 0$ is rejected and $\mathrm{H} 1$ accepted. So it can be concluded that there is a difference in literary skills 100 meters between the group of interval training method with the group of mixed exercise method and 100 meters student skill score trained by the interval method is superior / higher than the group value trained by the method mixed exercise for high-speed student reaction group at student of Faculty Of Teacher Training And Education Physical Education Health and Recreation Islamic University of Riau.

Based on the results of research and the results of the above analysis, it turns out the value of student skills trained by the method of interval training of high-speed reaction rate is superior to the method of high-speed reaction category reaction drills. Therefore, the authors recommend that the method of interval training for high reaction speed category is greater than the high-speed reaction category reaction technique in an attempt to improve the 100 meter running skill.

\section{Differences Results Running Skill 100 meters Between Continuous Training Method Category High reaction speed With Mix Practice Method Category High reaction speed In Student Physical Education Health and Recreation Islamic University of Riau. (A2B1xA3B1)}

As with group differences on the contrast of high-speed group reaction techniques and highspeed reaction group reaction methods, both treatment groups have a very significant difference. Results Contrast the value of both groups there is a p-value of 0.000 . When compared to the 0.05 or $5 \%$ significance standard p-value $0,000<0.05$ means $\mathrm{H} 0$ is rejected and $\mathrm{H} 1$ is accepted. So it can be concluded that there is a difference in literary skills value of 100 meters between the group of continuous training method with the group of high-speed reaction category reaction and mix of 100 meters student skill group which is trained by continuous group technique of high reaction speed is superior / high of the group value trained by the method of mix group reaction of high reaction speed at student Physical Education Health and Recreation Faculty Of Teacher Training And Education Islamic University of Riau.

The better the reaction rate is generally the better the chance of performing better running, and vice versa. Therefore a person who has a good rate of reaction is more likely to achieve a better quality of motion performance in a short period of time. interval training gives students the opportunity to explore their movements. In accordance with the form of exercise that is actually repetition. 
Based on the results of research and the results of the above analysis, it turns out the value of students' trained skills trained with the method of continuous training high reaction speed category is superior to the method of mixed practice of high speed co-op student. Therefore, the researcher recommends that the continuous practice method of high reaction speed category is greater than the high pressure reaction category reaction technique in an effort to improve the 100 meter running skill.

\section{Differences Results Running Skill 100 meters Between Methods Interval Training With Low Reaction Speed And Continuous Training Method With Low Reaction Speed At Student Physical Education Health and Recreation Islamic University of Riau(A1B2xA2B2)}

Based on the result of data analysis, it is stated that there is no difference of 100 meter skill score significantly between group of interval training method of low reaction speed category with group of continuous practice method of low reaction speed category.

From the results of the analysis of the method of exercise in the group of students with low reaction speed, when observed the implementation of both produce 100 meters running skills on students Physical Education Health and Recreation Faculty of Teacher Training and Education Islamic University of Riau. The result of analysis of interval training method with continuous practice method of low-speed student category was seen based on the result of variance analysis that is to see the difference between the two groups trained by interval training method with group of students trained by continuous technique method of the category of low reaction speed students. In contrast value of both treatment groups there is p-value value that is 0,413 . When compared to the 0.05 or $5 \%$ significance standard p-value $0.413>0.05$ means $\mathrm{H} 0$ is accepted and $\mathrm{H} 1$ is rejected. So it can be concluded that there is no difference in the value of literary 100 meter running skill between group of interval training method of low reaction speed category with group of continuous practice method of low reaction speed category and the value of 100 meter student skill group trained by interval category interval training method lower than the group value trained by the method of low speed reaction category training on students Physical Education Health and Recreation Faculty Of Teacher Training And Education Islamic University of Riau.

Based on the results of research and the results of the above analysis, it turns out the value of student skills trained with low-speed category interval training method is smaller / lower than the continuous practice method of low-speed student counseling category. Therefore, the authors recommend that the continuous low-reaction category (A2B2) clothing method is greater than the low-speed reaction category interval (A1B2) in an effort to improve the 100-meter running skill.

\section{Differences in Outcome Skills 100 meters Between Methods Interval Training Category Speed reaction Low And Mix Practice Method Category Low reaction speed In Student Physical Education Health and Recreation Islamic University of Riau (A1B2xA3B2)}

In performing treatment / treatment of low-speed student groups, educators provide extra training in delivering the material. Based on the results of data analysis revealed that there are differences in the value of 100 meter skill is real between the group of low-speed interval training method with low-speed reaction mix group.

From the results of the analysis of the method of exercise in the group of students with low reaction speed, when observed the implementation of both produce 100 meters running skills on students Physical Education Health and Recreation Faculty of Teacher Training and Education Islamic University of Riau. The result of the analysis of interval training method with the method of mixed student group practice of low reaction rate is seen based on the result of variance analysis that is to see the difference between the two groups trained by the interval training method with the group of students who are trained by the low-speed student reaction technique.

In contrast value of both treatment groups there are p-value value that is 0,0155 . When compared to the 0.05 or $5 \%$ significance standard p-value $0.0155<0.05$ means $\mathrm{H} 0$ is rejected and $\mathrm{H} 1$ 
is accepted. So it can be concluded that there are differences in the value of literary 100 meter running skills between groups of low-speed interval training methods with group of low-speed reaction category reaction training methods as well as 100 meters student skill score group of students trained by interval training method of low reaction speed more small / low than the value of the group trained by the method of low reaction speed reaction training on students Physical Education Health and Recreation Faculty Of Teacher Training And Education Islamic University of Riau.

Based on the results of the research and the results of the above analysis, it turns out the skill value of students trained by the method of interval training of low-speed reaction velocity is smaller / lower than the low-speed reaction category reaction mixture. Therefore, the researcher recommends that the method of mixed reaction of low reaction speed category is greater than the method of interval training of low reaction speed category in an effort to improve the 100 meter running skill.

\section{Differences Results Running Skill 100 meters Between Continuous Training Method Category Low reaction speed And Mix Exercise Method Category Low reaction speed In Student Physical Education Health and Recreation Islamic University of Riau (A2B2xA3B2).}

Group differences on contrast of continuous exercise values of low reaction speed category and low strength reaction rate reaction mixed methods, these two treatment groups had significant differences. Results Contrast the value of both groups there is a p-value value of 0.026 . When compared to the 0.05 or $5 \%$ significance standard p-value $0.026<0.05$ means $\mathrm{H} 0$ is rejected and $\mathrm{H} 1$ is accepted. So it can be concluded that there is a difference of 100 meter skill score significantly between group of continuous training method with group of low category reaction mix reaction technique and 100 meters student skill score which is trained by continuous group technique of low / low reaction low speed of the group value trained by the method of mix reaction group reaction speed is low on students Physical Education Health and Recreation Faculty Of Teacher Training And Education Islamic University of Riau.

Based on the results of research and the results of the above analysis, it turns out the value of student skills trained by the method of continuous training low reaction speed category is smaller / lower than the low-speed student rehearsal mix category. Therefore, the researcher recommends that the method of mixed reaction of low reaction speed category is greater than the continuous practice of low reaction speed category in an effort to improve the 100 meter running skill.

\section{CONCLUSION}

The conclusion of this study in accordance with the submission of hypotheses from the results of hypothesis testing can be drawn conclusion that

1) There is a difference between the interval training method and the continuous training method on 100 meter running skills. 2) There is a difference between the interval training method and the mixed training method of 100 meter running skills. 3) There is no difference between the method of continuous training with the method of mix training on 100 meter running skills on students Physical Education Health and Recreation Faculty Of Educational Science University of Islam Riau. 4) There is interaction effect between practice method and reaction speed to 100 meter running skill. 5) There is a difference in the result of the 100 meter running skill between the high speed reaction category interval training method and the continuous practice of high reaction speed category. 6) There is a difference in the result of 100 meter running skill between the interval method of high reaction speed category and the high pressure reaction mix category. 7) There is a difference in the result of the 100 meter running skill between the continuous practice of high reaction speed category and the high reaction rate reaction mix. 8) There is no difference in the result of the 100 meter running skill between the interval of the low reaction speed category with the continuous practice of low reaction speed category. 9) There is a difference in the result of a 100 meter running skill between the interval of the low reaction speed category interval and the low reaction rate reaction mixture. 10) There is 
difference of result of 100 meter running skill between continuous practice method of low reaction speed category with the method of mixed reaction of low reaction speed category on student Physical Education Health and Recreation Faculty Of Educational Science University University of Islam Riau.

\section{REFERENCE}

Abernethy, Bruce. et al. (2005). The Biophysical Foundations of Human Movement. (USA, Human Kinetik.

Adi, Winendra. (2008). Athletic Sports Series Running Throwing and Jumping. Yogyakarta, Pustaka Insan Madani.

Anwarudin, Sahadi.(2011). Basic Athletic Training. East Jakarta: PT. Container Science.

Arikunto, Suharisimi.(2013). Research Procedures A Practice Approach. Jakarta: PT. Rineka Cipta.

Aquatic Exercise Association.(2010). Aquatic Fitness Professional Manual. (Canada: Human Kinetik.

Atan, Tulin, Pelin Akyol. (2013). Reaction times of different branch athletes and correlation between reaction time parameters. Turkey: Elsevier.

Baechle, Thomas R. and Roger W. Earle.(2008). Essentials of Strength Training and Conditioning. Hong Kong: Human Kinetics.

Bana, O, E Mintarto, N W Kusnanik,(2018). The Effect of Acceleration Sprint and Zig-zag Drill Combination to Increase Students' Speed and Agility, Journal of Physics: Conf. Series,

Balyi, Istvan, Richard Way and Colin Higgs. (2013). Long-Term Athlete Development. USA, Human Kinetic.

Buckley, Roger and jim caple.(2009). The Theory and Practice Of Training. London and Philadelphia: Kogan Page.

Ciucurel, Manuela mihaela.(2012). The Relation Between Anxiety, Reaction Time And Performance Before And After Sport Competitions. Romania: Elsevier.

Cook, Gray. Atheletic Body In Balance. USA, Reebok University Master Trainer / Master Coach and Orthopedic and Sports Physical Therapy, Dunn, Cook, and Associates, 2003

Djumidar A. Widya, Mochmad.(2004). Learn To Play Basic Athletic Motions In Playing. Jakarta: PT Raja Gragindo Persada.

Echols, John M and Hassan Shadily.(2013). English-Indonesian dictionary. Jakarta: PT Gramedia Jakarta.

Faigenbaum, Avery D and Wayne L. Westcott.(2009). Young Strength Training. USA: Human Kinetics.

Farsani, Parisa Amiri and Davar Rezaeimanesh.(2011). The effect of six-week aerobic interval training on some blood lipids and VO2max in female athlete students.Iran: Elsevier.

Freeman, Will.(2014). Track \& Field Coaching Essentials. USA: Human Kinetics.

Vern Gambetta. (2007). Athletic development The Art \& Science of Functional Sports Conditioning. USA: Human Kinetick.

Gormley, John and Juliette Hussey.(2005). Exercise Therapy Prevention and Treatment Of Disease. USA: Blackwell.

Guthrie, Mark. (2003) Success Train Athletics. Reader Insan Madani.

Hanif, Achmad Sofyan. (2011). Sepaktakraw Basic Training. Jakarta: PT Bumi Timur Jaya.

Hari senjaya. 2007. Knowledge of Sports Hygiene Technique. PT. Refika Aditama, Member of IKAPI.

Hariris, Syamsuddin. (2002). The Basics of Coaching Science. Sukajadi: Vista Indah Printing, 2002.

Harrison, Andrew J, (2010). Biomechanical Factors In Sprint Training-Where Science Meets Coaching, XXVIII International Symposium of Biomechanics in Sports, Marquette, MI, USA.

Harsono.(2015). Sports coaching. Bandung: PT Remaja Rosdakarya.

Housewright, Ed.(2009). Winning Track And Field For Girls. New York: Chelsea House.

Herzog, Walter, (2016).Running slow or running fast; that is the question: The merits of highintensity interval training. Canada: Elsevier.

Hyde, Thomas E and Marianne S Gengenbach. (2005).Management Of Sport Injuries. USA. Lippincott Williams.

Tangkudung, James.(2012). Sports coaching. Jakarta: Smart Jaya. .(2016). Kinds of Research Methodology. Jakarta: Lens Media Media Indonesia. 
Junusul Hairy.(2003). Aerobic Endurance. Directorate General of Sport Ministry of National Education.

Kadir,(2010). Statistics For Social Science Research is equipped with SPSS Program Output. Jakarta: Rosemata Sampurna.

Kraemer, Wiliam J and Keiji Hakkinen.(2002). Strength Training For Sport. (USA Blackwel Science.

Kurdi, Fauziah Nuraini and Sukirno.(2012). The Basics of Sports Physiology. Palembang: Printing of Sriwijaya University.

Laelatul, goddess Badriah,(2009). Sports Physiology. Bandung: Multazam.

Purnomo, Eddy and Dapan. (2011) The Basics of Athletic Motion. Yogyakarta: Alfamedia.

Riduwan, (2009).Statistics Basics, Bandung: Alfabeta.

Rogers, Joseph L.(2000). USA Track \& Field Coaching Manual. USA: Human Kinetics.

Schmidt, Marcus,(2016).. IMU- Based Determination Of Stance Duration During Sprinting. Germany: Elsevier.

Shi, Qingde, Tomas K. Tong, (2018). Influence Of Recovery Duration During 6-S Sprint Interval Exercise On Time Spent At High Rates Of Oxygen Uptake. China: Science Direct.

Sidik, Dikdik Zafar.(2010). Teaching and Coaching Atlitik. Bandung: PT. Youth Rosdakarya Offset.

Sudarmada.(2015). Sports Biomechanics. Yogyakarta: Graha Ilmu.

Sugiyono.(2010). Educational Research Methods A Qualitative, Qualitative and R \& D Approach. Bandung: Alfabeta.

Sukadiyanto and Dangsina Muluk.(2011). Introduction to Theory and Methodology of Physical Training. Bandung: CV. Lubuk Agung.

Sukirno, (2012). Athletic Basics and Physical Exercise. Palembang: Printing of Sriwijaya University. (2008).Learning and Athletic Practice. Depok: Arya Duta.

Sutopo, Ari S. Alma Permana Lestari, and Team Revision Lab.(2006). Somatokinetika, Physiology Practical Guidebook Working Book (Ergophysiology). Jakarta: Faculty of Sport Science, Jakarta State University.

Syafrudin.(2011). Science of Sports Coaching. Padang: UNP Press Padang.

Tahmasebi, Shahzad and Boroujeni, Banafsheh Ghaheri.(2011). The Effect Of Motivational Self-Talk On Reaction Time. Iran: Elsevier.

Verducci, Frank R. (1980). Measurement Concept in Physical Education. St. Louis Missouri. Mosby Company.

Wiarto, Giri.(2013). Physiology and Sport. Yogyakarta: Graha Ilmu. . Athletics. Yogyakarta: Graha Ilmu.

Widiastuti. (2015). Test and Sport Measurements. Jakarta: PT Rajagrafindo Persada. 